\title{
Study on Purification Diatomite with nitric acid by Thermal Closed System
}

\author{
KUANG Meng ${ }^{1, \mathrm{a}}$, WANG Ping ${ }^{1, \mathrm{~b}}$, LUO Qiu-yun ${ }^{1}$, PENG Hu$^{1}$, WEI Yu-hong ${ }^{2}$ and WEI \\ Zhong-hua $^{2}$ \\ ${ }^{1}$ School of Material and Chemical Engineering, Jiangxi University of Science and Technology, \\ Ganzhou 341000, China; ${ }^{2}$ Guilin Xinzhu Natural Functional Material Co. Ltd., Guilin 541004
}

\begin{abstract}
In this research, a purification approach using nitric acid leaching at thermal closed system was developed to improve the porous structure of raw diatomite by removal of impurities from its surface and clogged pores. The feasibility and efficiency of this approach were determined by XRF for chemical constitution of diatomite, SEM for morphology and BET for specific surface area of purified diatomite. The investigations indicated that the content of $\mathrm{SiO}_{2}$ was in order of $85.14 \%$ for raw diatomite and $98 \%$ for purified diatomite, the content of $\mathrm{Fe}_{2} \mathrm{O}_{3}$ decreases after purified; the integrity of the porous structure was confirmed by SEM, and increase in specific surface area from $18 \mathrm{~m}^{2} \cdot \mathrm{g}^{-1}$ to $36 \mathrm{~m}^{2} \cdot \mathrm{g}^{-1}$.
\end{abstract}

Keyword: thermal closed system; diatomite; low temperature; purification

\section{Introduction}

Diatomite, is a sort of biologic sedimentary rock which composed of fossilized skeletons of diatoms with porous structure, it consists of amorphous silica $\left(\mathrm{SiO}_{2}\right)$ was derived from skeletons of diatoms, the remainder being $\mathrm{Al}_{2} \mathrm{O}_{3}, \mathrm{Fe}_{2} \mathrm{O}_{3}, \mathrm{CaO}, \mathrm{MgO}, \mathrm{K}_{2} \mathrm{O}$ and $\mathrm{Na}_{2} \mathrm{O}$ were adopted from clays and other minerals ${ }^{[1]}$. Due to well-developed porous structure with large specific surface area, diatomite possesses lots of excellent physical and chemical characteristics, such as low bulk density, chemical stability, high mechanical strength, and relatively low price owing to its abundance, etc. As a result of these features, it has been widely employed in variety of other applications: filter aid ${ }^{[2]}$, adsorbents ${ }^{[3]}$, and as support for catalysts ${ }^{[4]}$.

China has massive diatomite resources, but the vast majority of which are of low or moderate quality, and raw diatomite commonly contain several types of impurities, which block the porous and limit the performance. Therefore, it is purification of diatomite that will improve the property before its industrial and commercial utilization. It can be purified

First author: KUANG Meng (1990- ), male, Master candidate.

atE-mail: jxxskm@126.com.

*Correspondent author: WANG Ping (1958- ), male, Ph. D., Professor.

${ }^{\mathrm{b}}$ E-mail: wangp520@sina.com. 
by physical and chemical methods; these technologies have been basically mature that large grain minerals and clay minerals were removed by physical methods: scrubbing method, high-speed shear and ultrasonication. But these oxides where adhered at surface was removed by chemical methods: alkali leaching ${ }^{[5]}$, acid leaching ${ }^{[6]}$, and acid leaching-calcinations ${ }^{[7]}$. With these methods, nevertheless, have some drawbacks: destruction of the porous structure (alkali leaching); inefficiency, high operational cost, the pollution caused by sour vapors pours into air in open system (acid leaching and acid leaching-calcinations) could compromise the results.

Furthermore, the purification process can be accelerated if acid leaching temperatures were raised. For this reason, our idea was the raw materials (diatomite and nitric acid) were mixed in hydrothermal synthesis reactor (the model number is KH-500), heated. More specifically, the objective of our work was using acid leaching at thermal closed system and developed to improve the porous structure of raw diatomite by removal of impurities from its surface and clogged pores, loss of ignition (LOI) were removed by calcination at $450^{\circ} \mathrm{C}$.

\section{Experimental Part}

\subsection{Materials}

Nature diatomite from region of Jilin province in China was used in this investigation, after mining, primary crushing, blending and classifying of the raw diatomite, the natural powder was ready for use (with particle size distribution of $\mathrm{d}_{50}=20 \mu \mathrm{m}, \mathrm{S}_{\mathrm{BET}}=18 \mathrm{~m}^{2} \cdot \mathrm{g}^{-1}$ ). The chemical composition of which is shown in Table $1 . \mathrm{HNO}_{3}$ (A.R $65 \%$, by mass).

TABLE 1 CHEMICAL CONSTITUTION OF DIATOMITE (MASS FRACTION/\%)

\begin{tabular}{ccccccc}
\hline $\mathrm{SiO}_{2}$ & $\mathrm{Al}_{2} \mathrm{O}_{3}$ & $\mathrm{Fe}_{2} \mathrm{O}_{3}$ & $\mathrm{~K}_{2} \mathrm{O}+\mathrm{Na}_{2} \mathrm{O}$ & $\mathrm{CaO}+\mathrm{MgO}$ & $\mathrm{MnO}_{2}+\mathrm{TiO}_{2}$ & LOI \\
\hline 85.14 & 4.31 & 1.98 & 1.52 & 1.15 & 0.62 & 5.3 \\
\hline
\end{tabular}

\subsection{Purification of Diatomite}

The purified diatomite was prepared by mixing raw diatomite with $\mathrm{HNO}_{3}$ equilibrated for various contact time $4-14 \mathrm{~h}$. In this experiment, $80 \mathrm{~g}$ of diatomite, $150 \mathrm{ml}$ of $\mathrm{HNO}_{3}$ (in order to obtain complete reacted product, $\mathrm{HNO}_{3}$ was exceed the need) were mixed in hydrothermal synthesis reactor, sealed, and keep these samples at a constant temperature of $120^{\circ} \mathrm{C}$. The residual solid was separated from the mixture by washed several times with distilled water in centrifuge until $\mathrm{Fe}^{3+}$ can not be detected. The obtained samples were then dried in an oven at $70^{\circ} \mathrm{C}$, reground, and then samples were calcined at $450^{\circ} \mathrm{C}$, the purified diatomite were stored in tightly closed plastic bottles.

\subsection{Evaluation and Characterization}

For characterization of purified diatomite, several methods were used. The study of the samples included: (i) elemental analysis of the samples was carried out measurement X-ray fluorescence (S4 Pioneer), (ii) microstructural analysis using SEM (S-3400), and (iii) determination of specific surface areas by BET (BELSORP-mini II ). 


\section{Results and Discussion}

\subsection{Results of Purification}

Acid leaching process was solid-liquid multiphase reaction; this reaction can be described as:

$$
\sum\left(T_{x}^{n} \mathrm{O}_{y}^{m}+(x \cdot n) \mathrm{HCl} \rightarrow x T(\mathrm{Cl})_{n}+y \mathrm{H}_{2} \mathrm{O}\right)
$$

Where $T_{x}^{n} O^{m}{ }_{y}$ are $\mathrm{K}_{2} \mathrm{O}, \mathrm{Na}_{2} \mathrm{O}, \mathrm{CaO}, \mathrm{MgO}, \mathrm{Al}_{2} \mathrm{O}_{3}$ and $\mathrm{Fe}_{2} \mathrm{O}_{3}$; based on the motion of above oxides, $T_{x}^{n} O^{m}{ }_{y}$ in proper order with $\mathrm{HNO}_{3}$ start reaction. These results can be described as Table 2; it was found that the amount of $\mathrm{SiO}_{2}$ was in order of $85.14 \%$ for raw diatomite and $98 \%$ for purified diatomite, the content of $\mathrm{Fe}_{2} \mathrm{O}_{3}$ decreases after purified. $T^{n}{ }_{x} O^{m}{ }_{y}$ and partial organics were removed by acid leaching, then samples were washed, desiccations, calcined at $450^{\circ} \mathrm{C}$, adsorbed water and other organics were removed. As shown as in Table 2, acid leaching time was $8 \mathrm{~h}$, the reaction was basically over. From this knowable, the optimal conditions of acid leaching at $120^{\circ} \mathrm{C}$ for $8 \mathrm{~h}$ and calcination at $450^{\circ} \mathrm{C}$ for $2 \mathrm{~h}$.

TABLE 2 CHEMICAL CONSTITUTION OF DIATOMITE BEFORE AND AFTER PURIFICATION (MASS FRACTION/\%)

\begin{tabular}{cccccccc}
\hline Samples & $\mathrm{SiO}_{2}$ & $\mathrm{Al}_{2} \mathrm{O}_{3}$ & $\mathrm{Fe}_{2} \mathrm{O}_{3}$ & $\mathrm{~K}_{2} \mathrm{O}+\mathrm{Na}_{2} \mathrm{O}$ & $\mathrm{CaO}+\mathrm{MgO}$ & $\mathrm{MnO}_{2}+\mathrm{TiO}_{2}$ & LOI \\
\hline $\begin{array}{c}\text { Raw } \\
\text { diatomite }\end{array}$ & 85.14 & 4.31 & 1.98 & 1.52 & 1.15 & 0.62 & 5.3 \\
$4 \mathrm{~h}$ & 94.02 & 3.03 & 1.44 & 0.74 & 0.54 & 0.23 & - \\
$6 \mathrm{~h}$ & 97.88 & 1.01 & 0.36 & 0.48 & 0.13 & 0.13 & - \\
$8 \mathrm{~h}$ & 98.09 & 0.82 & 0.32 & 0.52 & 0.12 & 0.13 & - \\
$10 \mathrm{~h}$ & 98.16 & 0.78 & 0.33 & 0.44 & 0.14 & 0.15 & - \\
$12 \mathrm{~h}$ & 98.39 & 0.70 & 0.24 & 0.48 & 0.10 & 0.12 & - \\
$14 \mathrm{~h}$ & 98.51 & 0.64 & 0.30 & 0.29 & 0.10 & 0.16 & - \\
\hline
\end{tabular}

Note: Purified diatomite was treated using nitric acid concentration of $65 \%$ for $4 \mathrm{~h}$ to $14 \mathrm{~h}$ and calcined at $450^{\circ} \mathrm{C}$ for $2 \mathrm{~h}$.

\subsection{SEM of Diatomite}

The fresh sample was characterized by SEM, and selection of images of purified diatomite is presented in Fig. 1. The micrograph of $30 \mu \mathrm{m}$ diameter particles covered with diatoms and the shapes of diatom have disc and cylinder is shown in image (a); the porous structure of purified diatomite was well-developed and some holes could be seen in the surface more clearly, which suggests a porous and hollow structure as described previously is shown in image (b); in light of the above findings, microstructural analysis was done to verify the success of this approach in producing high purity diatomite and in maintaining 
the integrity of the porous structure of diatomite after purification is shown in (c) and (d). These results were in accordance with those of the preceding chemical analysis.

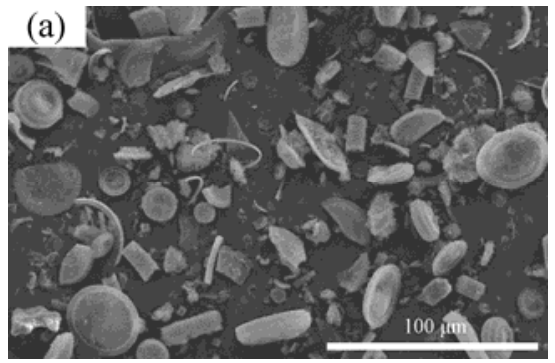

(c)

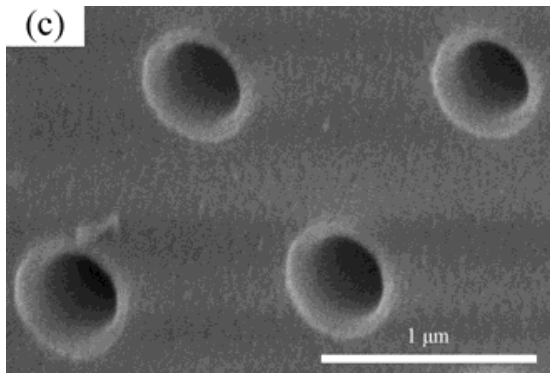

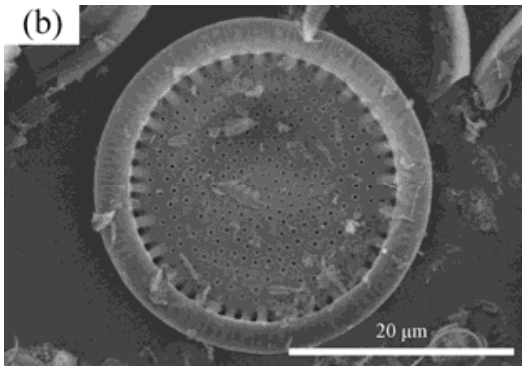

\section{(d)}

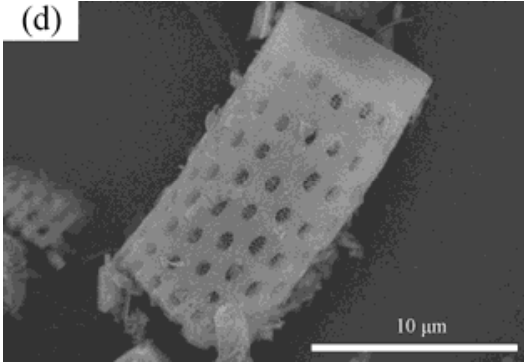

Fig. 1 Scanning electron microscope (SEM) photographs of purified diatomite

\subsection{BET Analysis}

Fig. 2 displays the nitrogen adsorption/deadsorption isotherms measured at $77 \mathrm{k}$ and pore size distributions was investigated using BJH method applied to purified diatomite. As shown as in Fig.2, the nitrogen adsorption isotherms for purified diatomite was classified as type II and pore size were $2.33 \mathrm{~nm}, 4.50 \mathrm{~nm}, 7 \mathrm{~nm}, 25.72 \mathrm{~nm}$ and $40 \mathrm{~nm}$, this means diatomite was mesoporous material according to International Union of Pure and Applied Chemistry (IUPAC).

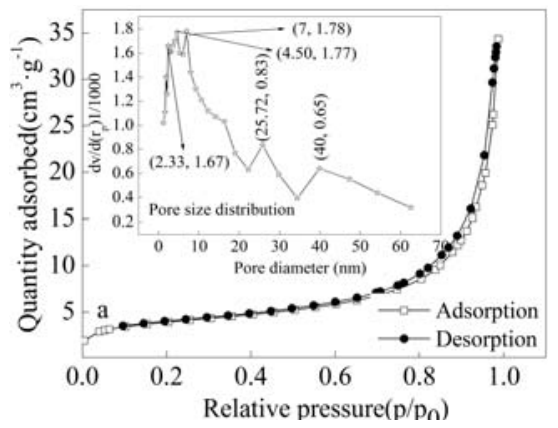

Fig.2 Isotherm for adsorption of $\mathrm{N}_{2}$ and pore size distribution on purified diatomite

Table 3 reveals the variation law of specific surface area, as shown as in it, increase in specific surface area from $18 \mathrm{~m}^{2} \cdot \mathrm{g}^{-1}$ to $36 \mathrm{~m}^{2} \cdot \mathrm{g}^{-1}$. 
TABLE 3 VARIATION LAW OF SPECIFIC SURFACE AREA OF PURIFIED

DIATOMITE

\begin{tabular}{ccccccc}
\hline Times $(\mathrm{h})$ & 0 & 4 & 6 & 8 & 10 & 14 \\
\hline $\begin{array}{c}\text { Specific surface area } \\
\left(\mathrm{m}^{2} \cdot \mathrm{g}^{-1}\right)\end{array}$ & 18 & 27.31 & 35.76 & 36.96 & 35.19 & 34.79 \\
\hline
\end{tabular}

\section{Conclusions}

It was shown in the present work that the treatment of diatomite with $\mathrm{HNO}_{3}$ in thermal closed system improved its purity. The amount of $\mathrm{SiO}_{2}$ was in order of $85.14 \%$ for raw diatomite and $98 \%$ for purified diatomite, the content of $\mathrm{Fe}_{2} \mathrm{O}_{3}$ decreases after purified. The well-develop porous structure was confirmed by SEM, and increase in specific surface area from $18 \mathrm{~m}^{2} \cdot \mathrm{g}^{-1}$ to $36 \mathrm{~m}^{2} \cdot \mathrm{g}^{-1}$.

\section{Acknowledgment}

The authors acknowledge with sincere gratitude the financial support provided by Nation Natural Science Foundation of China, project 41062002.

\section{References}

1. Angela F. Danil de Namor, Abdelaziz EI Gamouz, Sofia Frangie, et al. Turning the volume down on heavy metals using tuned diatomite. A review of diatomite and modified diatomite for the extraction of heavy metals from water [J]. Journal of Hazardous Materials, 2012, 241-242: 14-31.

2. Gómez J, Gil MLA, Rosa-Fox N. De, et al. Diatomite releases silica during spirit filtration [J]. Food Chemistry: 2014, 159: 381-387.

3. YE Xinxin, KANG Shenghong, WANG Huimin, et al. Modified natural diatomite and its enhanced immobilization of lead, copper and cadmium in simulated contaminated soils [J]. Journal of Hazardous Materials, 2015, 289: 210-218.

4. M.A. Kulagina, E.Yu. Gerasimov, T.Yu. Kardash, et al. A universal method to form $\mathrm{Pd}$ nanoparticles on low-surface-area inorganic powders and their support-dependent catalytic activity in hydrogenation of maleic acid [J]. Catalysis Today, 2015, 246: $72-80$.

5. ZHANG Jian, PING Qingwei, NIU Meihong, et al. Kinetics and equilibrium studies from the methylene blue adsorption on diatomite treated with sodium hydroxide [J]. Applied Clay Science: 2013, 83, 12-16.

6. ZHANG Guilong, CAI Dongqing, WANG Min, et al. Microstructural modification of diatomite by acid treatment, high-speed shear, and ultrasound [J]. Microporous and Mesoporous Materials: 2013, 165: 106-112.

7. Qodah Z.Al, Lafi W.K, Anber Z. Al, et al. Adsorption of methylene blue by acid and heat treated diatomaceous silica [J]. Desalination: 2007, 217: 212-224. 